\title{
SCREENING OF WHEAT (Triticum aestivum L.) VARIETIES WITH HIGH NITROGEN USE EFFICIENCY UNDER RAINFED AND IRRIGATED CONDITIONS
}

\author{
Jinwen YANG ${ }^{l}$, Yugang $S H I^{1}$, Huawei SHI ${ }^{1}$, Yubin WANG ${ }^{1,2}$, Wanghui GUAN ${ }^{l, 2}$ Xue YAN ${ }^{1}$, Shuguang \\ $W A N G^{l}$ and Daizhen $S U N^{1 *}$ \\ ${ }^{1}$ Shanxi Agricultural University, College of Agronomy, Taigu, P.R.CHINA \\ ${ }^{2}$ Institute of Sorghum, Shanxi Academy of Agricultural Sciences, Jinzhong, P.R.CHINA \\ *Corresponding author: sdz64@126.com
}

Received: 28.09 .2018

\begin{abstract}
The aim of this study was to clarify the relationship of nitrogen accumulation and transport with yield of wheat and determine the indicators for the screening of wheat varieties with high nitrogen use efficiency (NUE). A total of sixteen winter wheat (Triticum aestivum $L$.) varieties were used to determine fourteen nitrogen accumulation and transport-related traits as well as yield-related traits in field under irrigated and rainfed conditions. The correlations between the major nitrogen accumulation and transport-related traits and yield traits of wheat were analyzed, and the nitrogen use type of the wheat varieties was classified. Results showed that eight nitrogen accumulation and transport-related traits had significant or highly significant genetic correlations with yield per plant under the two water regimes. These eight traits were transport amount of pre- flowering reserve nitrogen and contribution of pre-flowering reserve nitrogen to grain nitrogen, nitrogen accumulation and transport amount after flowering, nitrogen transport efficiency after flowering, contribution of nitrogen assimilation to grain nitrogen after flowering, nitrogen utilization efficiency for grain production and biomass production. These eight traits were used as indicators for a comprehensive clustering of the wheat materials, and the sixteen varieties were classified into three groups representing the high NUE, intermediate, and low NUE types, respectively. From the perspective of nitrogen utilization, efforts must be made in the following aspects to obtain higher yields regardless of irrigated or rainfed conditions: 1) to improve nitrogen utilization efficiency for grain production and biomass production, as well as nitrogen accumulation and transport amount after flowering, nitrogen transport efficiency and contribution of nitrogen assimilation to grain nitrogen after flowering, and 2) to decrease transport amount of pre- flowering reserve nitrogen and contribution of pre-flowering reserve nitrogen to grain nitrogen.
\end{abstract}

Keywords: Clustering analysis, genetic correlation, high nitrogen use efficiency, nitrogen accumulation, nitrogen transport, winter wheat

\section{INTRODUCTION}

As a major food crop, wheat (Triticum aestivum L.) plays a significant role in safeguarding food security in China (Etienne et a1., 2012; Shi et al., 2012; Wang et al., 2012). In recent years, there has been a blind pursuit of increasing the yield per unit area in production to meet the growing demand for wheat, which results in a gradual increase in the rate of nitrogen application (Gevrek et a1., 2012; Mohammadi et al., 2012). However, excessive application of nitrogen has caused serious damage to the environment and also led to a series of problems such as a reduction of nutrient utilization efficiency in crops and an increase of production cost (Nadine et al., 2010; Kong et al., 2010; Lobell et al., 2011; Townsend et al., 2010). How to improve nitrogen utilization efficiency and reduce nitrogen application rate is currently an urgent problem to be solved in wheat production. Studies have shown that different varieties of the same crop have varying capacities for nitrogen uptake and utilization (Wang et al., 2010; Erdle et al., 2013; Oury et al., 2012). Therefore, screening of varieties with high nitrogen use efficiency (NUE) is an effective approach to improve nitrogen utilization efficiency and reduce nitrogen application rate in wheat (Graybosch et al., 2012; Lopez et al., 2012; Green et al., 2012).

The nitrogen utilization efficiency of crops is correlated with multiple traits (Zhao et al., 2012; Xu et al., 2017). Therefore, full consideration should be given to other traits related to the nitrogen utilization efficiency of crops in the screening of high NUE varieties. Zhang et al. (2010) found that high NUE genotypes of wheat had higher leaf water potential and chlorophyll content than low NUE wheat; thus, leaf water potential and chlorophyll content were regarded to be indicators for the screening of 
high NUE genotypes. Ruby et al. (2012) screened high NUE and low NUE wheat materials under hydroponic conditions with low nitrogen and high nitrogen levels, by using fresh weight, dry weight, root length, plant height, and root nitrogen uptake efficiency as the indicators. Khalid et al. (2012) screened wheat varieties with high efficiency of nitrogen uptake and utilization through hydroponic experiments using nitrogen utilization efficiency as the indicator. Wang et al. (2010) selected two wheat varieties with high nitrogen uptake and utilization efficiency under high nitrogen and low nitrogen conditions by using nitrogen harvest index, stem dry weight, grain nitrogen content, stem nitrogen content, plant total nitrogen content, nitrogen uptake efficiency, nitrogen physiological efficiency, and nitrogen utilization efficiency as the indicators. Through hydroponic experiments, Li et al. (2009) systematically evaluated the genotypic differences of low-nitrogen tolerance in seedlings of thirty-two wheat varieties bred in different ages, and the thirty-two varieties were divided into low-nitrogen sensitive, intermediate, and low-nitrogen tolerant types ( Ruan et al., 2016) successfully screened high NUE lines in one hundred thirty eight recombinant inbred lines of rice using nitrogen utilization efficiency for grain production and biomass production, stem nitrogen content, leaf nitrogen content, spike nitrogen content, spike length, stem weight per plant, total dry weight per plant, grain weight per plant, seed setting rate, thousand kernel weight, and plant height of rice as the indicators.

According to the above introduction, previous studies on the screening of wheat materials with high NUE have the following characteristics. First, hydroponic experiments were performed in some of the studies (Ruby et al., 2012; Khalid et al., 2012), whether the results can guide field production remains to be tested. Second, different nitrogen levels were set in the field for relevant studies (Wang et al., 2010), the high NUE varieties screened by this method are only applicable to high-input environment. As we know, reducing the application of nitrogen fertilizer is the direction of future development to reduce the environmental pollution caused by excessive nitrogen application; thus, the study results cannot better guide the high-NUE breeding and production practices of wheat. Third, researchers only set different nitrogen levels in the field trials, while they did not taken into account the effect of another important factor, water shortage in soil, on nitrogen uptake and utilization in wheat. In the present study, we used sixteen winter varieties and set an intermediate nitrogen level in the field to analyze nitrogen accumulation and transport-related traits in wheat under rainfed (dry soil moisture) and irrigated ( adequate soil moisture) conditions. Combined with the yield and yield components, we classified the wheat varieties and screened high NUE varieties. The results lay a foundation for the screening of high NUE materials of wheat.

\section{MATERIALS AND METHODS}

\section{Experimental materials}

A total of sixteen winter varieties were used in the study, including Jinmai 54, Jinmai 66, Jinmai 72, Jinmai 73, FRFSCD, Nongda 92-101, Jinmai 61, Taimai 269, Xin 9152, Lankao 1, Tangmai 5012, Tainong 18, S707-3, S707-4, Chang 6135 and Xindasui.

\section{Experimental design}

The experiments were carried out in two years. During 2014-2015, the experiments were conducted in the wheat experimental field at the agricultural station of Shanxi Agricultural University $\left(37^{\circ} 25^{\prime} \mathrm{N}, 112^{\circ} 25^{\prime} \mathrm{E}\right)$. The soil (0-20 cm depth) contained $0.784 \%$ organic matter, 5.1 $\mathrm{g} \cdot \mathrm{kg}^{-1}$ total nitrogen, $7.61 \mathrm{mg} \cdot \mathrm{kg}^{-1}$ available phosphorus, and $125 \mathrm{mg} \cdot \mathrm{kg}^{-1}$ available potassium, with a sandy texture. Pure nitrogen $\left(150 \mathrm{~kg} \cdot \mathrm{ha}^{-1}\right)$ was applied once as a base fertilizer at sowing. Two water regimes were set, rainfed and irrigation, which were separated by a $1.5 \mathrm{~m}$ isolation zone. The experiments had three repetitions and used a randomized block design. There were two rows per plot and 40 seeds were drilled in each row. Rows were $0.25 \mathrm{~m}$ apart and $2 \mathrm{~m}$ long. Seeds were sown on September 23, 2014. The rainfed treatment received no water during the growth period and only natural precipitation was used; the rainfall throughout the whole growth period was 218.4 $\mathrm{mm}$. Irrigated plots were well watered using sprinkle irrigation at the overwintering, reviving, jointing, and grain-filling stages to ensure adequate supply of water throughout the whole growth period. The total amount of irrigation was equivalent to $650 \mathrm{~mm}$ rainfall. The experiments had three repetitions and used a randomized block design. There were two rows per plot and 40 seeds were drilled in each row. Rows were $0.25 \mathrm{~m}$ apart and $2 \mathrm{~m}$ long. Seeds were sown on September 23, 2014. From October 2014 to June 2015, the monthly average atmospheric temperature was $12.1^{\circ} \mathrm{C}, 3.3^{\circ} \mathrm{C},-4.2^{\circ} \mathrm{C}$, $-2.9^{\circ} \mathrm{C},-0.8^{\circ} \mathrm{C}, 7^{\circ} \mathrm{C}, 13.1^{\circ} \mathrm{C}, 19.2^{\circ} \mathrm{C}, 22.8^{\circ} \mathrm{C}$ respectively, and activity accumulated temperature was $2026.39^{\circ} \mathrm{C}$. Wheat was harvested in June 24-25, 2015.

During 2015-2016, the experiments were conducted in the wheat experimental field at the agricultural station of Shanxi Agricultural University. The soil (0-20 cm depth) contained $0.982 \%$ organic matter, $7.9 \mathrm{~g} \cdot \mathrm{kg}^{-1}$ total nitrogen, $11.4 \mathrm{mg} \cdot \mathrm{kg}^{-1}$ available phosphorus, and $136.7 \mathrm{mg} \cdot \mathrm{kg}^{-1}$ available potassium, with a sandy texture. Pure nitrogen $\left(150 \mathrm{~kg} \cdot \mathrm{ha}^{-1}\right)$ was applied once as a base fertilizer at sowing. The experimental design was the same as used in 2014-2015 and the date of seed sowing was September 25, 2015. The rainfall during the whole growth period was $256.9 \mathrm{~mm}$ and the irrigation treatment was performed as did in the previous year. From October 2015 to June 2016, the monthly average atmospheric temperature was $11^{\circ} \mathrm{C}$, $3.7^{\circ} \mathrm{C},-1.4^{\circ} \mathrm{C},-5.7^{\circ} \mathrm{C},-1.4^{\circ} \mathrm{C}, \quad 6.2^{\circ} \mathrm{C}, 15.1^{\circ} \mathrm{C}, 18.2^{\circ} \mathrm{C}$, $21.8^{\circ} \mathrm{C}$ respectively, and activity accumulated temperature 
was $1985.56^{\circ} \mathrm{C}$. Wheat was harvested in June 25-26, 2016. Results of the two years were averaged during data analysis.

\section{Sample collection}

At the flowering stage (when $50 \%$ of the spikes were in bloom), thirty wheat plants per replication with uniform flowering, normal development, and similar growth were selected and tagged for each variety. After flowering, three plants were selected and gently pulled with roots every 7 days. The roots were cut and the shoots were deactivated in an oven for $15 \mathrm{~min}$ at $105^{\circ} \mathrm{C}$, followed by drying at $80^{\circ} \mathrm{C}$. Leaf, stem, spike stalk and grain samples were weighed separately and placed into paper bags. The sampling dates were $7,14,21,28,35$, and 42 days after flowering.

\section{Experimental methods}

\section{Determination of total nitrogen content}

Total nitrogen content was determined by intermittent chemical analysis (Tu et al., 2013).

Nitrogen accumulation, transport, transport efficiency, and contribution rate were calculated as follows (Moll et al., 1982):

Nitrogen accumulation $($ NA $)=$ Plant nitrogen content $\times$ plant dry weight

Nitrogen transport amount before flowering (NTABF) $=\mathrm{NA}$ at flowering - nitrogen accumulation in vegetative organs at maturity

Nitrogen transport efficiency before flowering $(\mathrm{NTEBF})=\mathrm{NTABF} / \mathrm{NA}$ at flowering $\times 100$

Contribution of pre-flowering reserve nitrogen to grain nitrogen $(\mathrm{CPRNGN})=\mathrm{NTEBF} /$ grain nitrogen accumulation at maturity $\times 100$

Nitrogen transport amount after flowering $(\mathrm{NTAAF})=$ Grain nitrogen accumulation at maturity $-\mathrm{NTABF}$

Nitrogen transport efficiency after flowering (NTEAF) $=$ Nitrogen transport into grains after flowering (whole plant) / (NA at maturity - nitrogen accumulation in vegetative organs at flowering) $\times 100$

Contribution of nitrogen assimilation to grain nitrogen after flowering $(\mathrm{CNAGNF})=\mathrm{NTAAF} /$ grain nitrogen accumulation at maturity $\times 100$

Nitrogen utilization efficiency for grain production (NUEg): the ratio of grain yield per plant and total amounts of accumulated nitrogen per plant.

Nitrogen utilization efficiency for biomass production (NUEb): the ratio of total dry matter accumulation per plant and total amounts of accumulated nitrogen per plant.

Nitrogen harvest index (NHI): the percentage of grain nitrogen accumulation per plant in the total nitrogen accumulation per plant.

\section{Wheat test at harvest}

After wheat maturity, 10 plants per replication were selected at random from each variety. The plants were gently pooled with roots and air-dried. The average of 10 plants was taken as the observation value for each variety. We analyzed effective tillers (ET), spikelet number (SN), effective spikelet number (ESN), grain number of main spikes (MSGN), grain weight of main spikes (MSGW), thousand kernel weight (TKW) and yield per plant (YPP).

\section{Phenotypic and genetic correlation analysis}

Correlation coefficients were calculated as follows (Shi et al., 2017):

$$
r_{p x y}=\frac{C O V_{p x y}}{\sqrt{V_{p x} V_{p y}}}
$$

where $r_{p x y}$ represents the phenotypic correlation coefficient; $C O V_{p x y}$ represents the phenotypic covariance of traits $x$ and $y ; V_{p x}$ and $V_{p y}$ represent the phenotypic variance of $x$ and $y$ respectively.

$$
r_{g x y}=\frac{C O V_{g x y}}{\sqrt{V_{g x} V_{g y}}}
$$

where $r_{g x y}$ represents the genetic correlation coefficient; $C O V_{g x y}$ represents the genetic covariance of traits $\mathrm{x}$ and $\mathrm{y}$; $V_{p x}$ and $V_{p y}$ represent the genetic variance of $\mathrm{x}$ and $\mathrm{y}$ respectively.

\section{Statistical analysis}

Data were statistically analyzed using Excel 2010 (Microsoft Corp., Redmond, WA, USA) and SPSS 19.0 statistical software (IBM SPSS, SomerS, NY, USA).

\section{RESULTS}

\section{Differences of nitrogen accumulation and} transport-related traits in wheat varieties under irrigated and rainfed conditions

There were variability of 14 nitrogen accumulation and transport-related indicators in different wheat varieties under two water regimes (Table 1). Under irrigated condition (well-watered, WW), the NABF, NHI and NTEBF had small coefficients of variation (2.9-4.91\%), while the remaining 11 indicators had large coefficients of variation (13.6-37\%) greater than 10\%. Under rainfed condition (drought stress, DS), the NHI and NTEBF had small coefficients of variation (2.7 and $4.2 \%$, respectively), while the remaining 12 indicators had large coefficients of variation (11.3-37.1\%) greater than $10 \%$. The large coefficients of variation indicated that there existed great differences in these indicators among the wheat varieties.

There were significant differences in the NTABF, CPRNGN, NTAAF and CNAGNF of wheat varieties between irrigated and rainfed conditions. In addition, 
highly significant differences were also found in the NABF, NAAF and MLN/TN. These results indicated that the water regimes had an impact on nitrogen accumulation and transport in the wheat varieties.

Table 1. Variability of nitrogen accumulation and transport-related traits in wheat varieties under irrigated and rainfed conditions

\begin{tabular}{|c|c|c|c|c|c|c|c|c|c|c|c|}
\hline \multirow{2}{*}{ Trait } & \multicolumn{5}{|c|}{ WW } & \multicolumn{5}{|c|}{ DS } & \multirow{2}{*}{ t value } \\
\hline & Mean & Variance & SD & SE & $\mathrm{CV}$ & Mean & Variance & SD & SE & $\mathrm{CV}$ & \\
\hline NABF (mg.plant ${ }^{-1}$ ) & 268.435 & 178.111 & 13.346 & 7.705 & 4.91 & 229.105 & 670.235 & 25.889 & 14.099 & 11.30 & $4.83 * *$ \\
\hline NAAF (mg.plant $\left.{ }^{-1}\right)$ & 327.712 & 2165.516 & 46.535 & 26.207 & 14.20 & 290.505 & 1155.258 & 33.989 & 20.666 & 11.70 & $5 * *$ \\
\hline MLN/TN(\%) & 1.894 & 0.456 & 0.675 & 0.169 & 37.00 & 1.104 & 0.169 & 0.410 & 0.103 & 17.50 & $7.29 * *$ \\
\hline MSN/TN (\%) & 10.876 & & & 0.481 & 23.50 & & & 2.058 & & & 1.72 \\
\hline & 5.58 & & & & 17.90 & & & 1.333 & & & 9 \\
\hline & 0.1 & & & 007 & 26.80 & & & 0.017 & 0.004 & 19.30 & 4 \\
\hline & & & & 0.006 & 2.90 & & & 0.024 & 0.006 & 2.70 & 0.99 \\
\hline $\mathrm{NUEb}$ & 0.33 & & 0.0 & 0.020 & 24.20 & 0.3 & & 0.066 & 0.017 & 21.10 & 0.26 \\
\hline NTAB & 172.508 & 550. & & 13.135 & 13.60 & 165. & & 24.042 & 13.138 & 14.50 & $2.15^{*}$ \\
\hline NTEBF & 78.412 & 8.416 & 2.901 & 0.762 & 3.70 & 76.988 & 10.452 & 3.233 & 1.859 & 4.20 & 0.26 \\
\hline CPRNGN (\%) & 67.120 & 214.059 & 14.632 & 7.896 & 21.80 & 63.4 & 142.444 & 11.935 & 7.585 & 18.80 & $-2.18 *$ \\
\hline NTAAF (mg.plant ${ }^{-1}$ ) & 150.304 & 748.296 & 27.355 & 15.568 & 18.20 & 133.239 & 471.671 & 21.718 & 12.797 & 16.30 & $2.16^{*}$ \\
\hline $\operatorname{NTEAF}(\%)$ & 76.039 & 345.365 & 18.584 & 11.942 & 21.60 & 74.962 & 440.412 & 20.986 & 12.646 & 24.70 & 1.81 \\
\hline CNAGNF (\%) & 37.639 & 184.175 & 13.571 & 3.393 & 36.10 & 32.851 & 148.483 & 12.185 & 3.046 & 37.10 & $2.57 *$ \\
\hline
\end{tabular}

Note: WW, well-watered; DS, drought stress; NABF and NAAF, the amounts of accumulated nitrogen before and after flowering, respectively; MLN/TN, MSN/TN, and MGN/TN, the ratios of leaf, stem, and spike stalk nitrogen / total nitrogen at maturity, respectively; NUEg, nitrogen utilization efficiency for grain production; NHI, nitrogen harvest index; NUEb, nitrogen utilization efficiency for biomass production; NTABF, ntrogen transport amount before flowering; NTEBF, nitrogen transport efficiency before flowering; CPRNGN, contribution of pre-flowering reserve nitrogen to grain nitrogen; NTAAF, nitrogen transport amount after flowering; NTEBF, nitrogen transport efficiency after flowering; and CNAGNF, contribution of nitrogen assimilation to grain nitrogen after flowering.

Note:*and**, Significant at 0.05 and 0.01 probability levels, respectively.

\section{Principal component analysis of nitrogen accumulation and transport-related indicators in wheat varieties under irrigated and rainfed conditions}

Among the fourteen nitrogen accumulation and transport-related indicators reported in the above section, which are the main indicators affecting nitrogen accumulation and transport in wheat? To answer this question, we performed a principal component analysis on those indicators with the coefficient of variation greater than $10 \%$.

Table 2. Principal component analysis of nitrogen accumulation and transport-related indicators of wheat varieties under irrigated and rainfed conditions

\begin{tabular}{lcccccc}
\hline Evn. & \multicolumn{3}{c}{ WW } & & \multicolumn{2}{c}{ DS } \\
\hline Item & Facter1 & Facter2 & Facter3 & Facter1 & Facter2 & Facter3 \\
\hline Eigenvalue & 7.1918 & 1.2889 & 1.1664 & 7.0001 & 1.6627 & 1.304 \\
Contribution rate & 65.3796 & 11.717 & 10.6035 & 58.3338 & 13.8562 & 10.8671 \\
Cumulative contribution rate $_{\text {NABF (mg.plant }{ }^{-1} \text { ) }}$ & 65.3796 & 77.0967 & 87.7002 & 58.3338 & 72.19 & 83.0571 \\
NAAF (mg.plant ${ }^{-1}$ ) & & & & -0.2466 & 0.5758 & 0.0112 \\
MLN/TN & 0.3260 & 0.2614 & -0.2078 & 0.2330 & 0.5737 & -0.1834 \\
MSN/TN & 0.1306 & 0.6668 & 0.2313 & 0.0324 & 0.1880 & 0.2271 \\
MGN/TN & 0.1683 & -0.6104 & -0.1211 & 0.1092 & 0.0010 & 0.7217 \\
NUEg & 0.0008 & -0.0950 & 0.8947 & 0.1283 & 0.3182 & 0.5392 \\
NUEb & 0.3007 & -0.1305 & 0.0210 & 0.3285 & -0.0845 & 0.0917 \\
NTABF & 0.3493 & 0.0338 & -0.0532 & 0.3337 & -0.0894 & 0.0286 \\
CPRNGN & -0.3109 & 0.2810 & -0.2718 & -0.3187 & 0.3771 & -0.1457 \\
NTAAF & -0.3682 & -0.0133 & -0.0273 & -0.3691 & -0.0789 & 0.1295 \\
NTEAF & 0.3645 & 0.0880 & -0.0974 & 0.3588 & 0.1764 & -0.1346 \\
CNAGNF & 0.3678 & 0.0135 & 0.0004 & 0.3632 & 0.0583 & -0.1547 \\
\hline
\end{tabular}

Under rainfed condition, the cumulative contribution rate of the first three principal components was $83.0571 \%$
Under irrigated condition, the cumulative contribution rate of the first three principal components was $87.7002 \%$ (Table 2), which exceeded the general requirement of $80 \%$. This indicated that these three principal components represented the majority of the variation in the indicators for nitrogen accumulation and transport among different wheat varieties. A comprehensive analysis of the compositional loading of these three principal components showed that the major indicators for nitrogen accumulation and transport under irrigated condition were NAAF, MSN/TN, NUEg, NUEb, NTABF, CPRNGN, NTAAF, NTEAF and CNAGNF. 
the major indicators for nitrogen accumulation and transport under rainfed condition were NAAF, MGN/TN, NUEg, NUEb, NTABF, CPRNGN, NTAAF, NTEAF and CNAGNF.

\section{Correlation between nitrogen accumulation and} transport-related traits and yield traits of wheat varieties under two water regimes

The correlation between the nine major nitrogen accumulation and transport-related traits and YPP were analyzed under irrigated condition (Table 3 ). The results showed that NUEg, NUEb, NTAAF and CNAGNF had significant or highly significant phenotypic correlations with YPP (correlation coefficient $r=0.4853-0.6587$ ). In addition, NAAF, NUEg, NUEb, NTAAF, NTEAF and CNAGNF had significant or highly significant genetic correlations with YPP $(\mathrm{r}=0.5350-0.7836)$. The same indicator showed a higher genetic correlation than phenotypic correlation with YPP, indicating that these indicator traits were less affected by environmental factors. In addition, there were different levels of genetic and phenotypic correlation between these nitrogen utilization indicators and yield components, while NTABF and CPRNGN had significant or highly significant genetic and phenotypic negative correlations with most of these indicator traits. These correlations suggested that some of the traits may have mutual restriction and mutual influence with each other. It is possible that pleiotropism or linkage exists in genes that control these traits.

We also analyzed the correlation between the nine major nitrogen accumulation and transport-related traits and yield indicators were also analyzed under rainfed condition (Table 3). The results showed that NAAF, NUEg, NUEb, NTAAF, NTEAF and CNAGNF had significant or highly significant phenotypic and genetic correlations with YPP $(\mathrm{r}=0.5171-0.9249)$. The same indicator had higher genetic correlation than phenotypic correlation with YPP, indicating that these indicator traits were less affected by environmental factors. Moreover, NTABF and CPRNGN had negative genetic and phenotypic correlations with YPP, and the genetic correlation reached a significant or highly significant level. Furthermore, there were different levels of genetic and phenotypic correlations between these nitrogen accumulation and transport-related traits and yield indicators.

\section{Clustering analysis of major nitrogen accumulation and transport-related traits and yield indicators of wheat varieties under irrigated and rainfed conditions}

According to the above correlation analysis, NAAF, NUEg, NUEb, NTAAF, NTEAF, CNAGNF ,NTABF and CPRNGN had significant or highly significant genetic correlations with YPP under the two water regimes. On this basis, we performed a clustering analysis on the wheat varieties using these eight indicators.

Under irrigated condition, the wheat varieties were classified into three groups at the average linkage of 1.52
(Figure 1). Group I was the high NUE type, including Jinmai 54, Jinmai 66, FRFSCD and S707-3, these four varieties had a mean YPP of $6.13 \mathrm{~g}$, with higher NAAF, NUEg, NUEb, NTAAF, NTEAF, CNAGNF, and lower NTABF and CPRNGN (Table 4). Group III was the low NUE type, including Jinmai 61, Lankao 1, Tangmai 5012, and Tainong 18, these four varieties had a mean YPP of $3.79 \mathrm{~g}$, with lower NAAF, NUEg, NUEb, NTAAF, NTEAF, CNAGNF, and higher NTABF and CPRNGN (Table 4). Group II was the intermediate type, including the remaining eight varieties, which had a mean YPP of $5.17 \mathrm{~g}$, the mean values of their major nitrogen utilization indicators were between the former two groups (Table 4).

Under rainfed condition, the wheat varieties were divided also into three groups at the average linkage of 1.63(Figure 2). Group I was the high NUE type, including Jinmai 54, Jinmai 66, FRFSCD, S707-3 and Xindasui, these five varieties had the mean YPP of $5.50 \mathrm{~g}$, with higher NAAF, NUEg, NUEb, NTAAF, NTEAF, CNAGNF, and lower NTABF and CPRNGN (Table 4). Group III was the low NUE type, including Jinmai 72, Tainong 18, Jinmai 73 and Jinmai 61, these four varieties had the mean YPP of $3.47 \mathrm{~g}$, with lower NAAF, NUEg, NUEb, NTAAF, NTEAF, CNAGNF , and higher NTABF and CPRNGN (Figure 2). Group II was the intermediate type, including the remaining seven varieties, their mean YPP was $4.58 \mathrm{~g}$ and the mean values of the major nitrogen utilization indicators were between the former two groups (Figure 2).

\section{DISCUSSION}

\section{Screening of major indicators affecting nitrogen accumulation and transport in wheat}

There are genotypic differences in nitrogen uptake, accumulation and distribution of wheat varieties (Karrou et al., 1994; Foulkes et al., 1998), which makes it possible to screen wheat varieties with high NUE. Therefore, it is critical to establish the evaluation indicators of high NUE varieties. Zhou et al. (2000) thought that there are differences among wheat varieties in terms of total nitrogen demand, staged nitrogen uptake, nitrogen uptake intensity, nitrogen utilization efficiency, stem nitrogen content, and NHI. They believed that these indicators are of great reference value for the screening of wheat varieties with high NUE. Vose et al. (1984) suggested that nitrogen utilization efficiency is affected by multiple factors such as nitrogen uptake, Nitrare Reductase Activity, $\mathrm{NO}_{3}{ }^{-}$storage level, and capacity of nitrogen transport to harvested organs. Here, fourteen nitrogen accumulation and transport-related traits in sixteen wheat varieties were determined under irrigated and rainfed conditions. Eight major indicator traits that affected nitrogen accumulation and transport in wheat were identified. They were NAAF, NUEg, NUEb, NTABF, CPRNGN, NTAAF, NTEAF and CNAGNF. Clearly, our results were not exactly the same as previous researches. The reasons may be that there were differences in water conditions and nitrogen levels. 
Table 3. Genetic correlation coefficients between major nitrogen accumulation and transport-related traits and yield of wheat varieties under irrigated and rainfed condition

\begin{tabular}{|c|c|c|c|c|c|c|c|c|c|c|c|c|c|c|c|c|c|}
\hline \multirow[t]{2}{*}{ ENV } & \multirow{2}{*}{$\begin{array}{c}\text { Indicator } \\
\mathrm{NABF}\end{array}$} & \multirow{2}{*}{$\begin{array}{c}\text { NABF } \\
-\end{array}$} & \multirow[t]{2}{*}{ MLN/TN MGN/TN } & \multirow[t]{2}{*}{ NUEg } & \multirow[t]{2}{*}{$\mathrm{NUEb}$} & \multirow[t]{2}{*}{ NAAF } & CPRNGN & \multicolumn{3}{|c|}{ NTAAF NTEAF CNAGNF } & \multirow[t]{2}{*}{$\mathrm{SN}$} & \multirow[t]{2}{*}{ ESN } & \multirow[t]{2}{*}{ ET } & \multirow[t]{2}{*}{ MSGN } & \multirow[t]{2}{*}{ MSGW } & \multicolumn{2}{|c|}{ TKW YPP } \\
\hline & & & & & & & & & & & & & & & & & \\
\hline & MLN/TN & 0.418 & - & & & & & & & & & & & & & & \\
\hline & NUEg & $0.681 * *$ & 0.046 & - & & & & & & & & & & & & & \\
\hline & NUEb & $0.844 * *$ & 0.312 & $0.908 * *$ & - & & & & & & & & & & & & \\
\hline & NAAF & $-0.486^{*}$ & -0.179 & $-0.624 *$ & $-0.692 * *$ & - & & & & & & & & & & & \\
\hline & CPRNGN & $-0.847 * *$ & -0.366 & $-0.735 * *$ & $-0.8858 *$ & $0.864 * *$ & - & & & & & & & & & & \\
\hline & NTAAF & $0.943 * *$ & 0.353 & $0.756 * *$ & $0.903 * *$ & $-0.743 * *$ & $-0.970 * *$ & - & & & & & & & & & \\
\hline & NTEAF & $0.853 * *$ & 0.346 & $0.74 * *$ & $0.886 * *$ & $-0.856^{* *}$ & $-0.999 * *$ & $0.973^{* *}$ & $k \quad-$ & & & & & & & & \\
\hline & ${ }^{G C}$ CNAGNF & $0.845^{* *}$ & 0.363 & $0.734 * *$ & $0.884 * *$ & $-0.867 * *$ & $-1.000 * *$ & $0.969 * *$ & $0.999 * *$ & - & & & & & & & \\
\hline & SN & $0.454 *$ & 0.305 & $0.700 * *$ & $0.784 * *$ & -0.436 & $-0.568 *$ & $0.524 *$ & $0.569 *$ & $0.566^{*}$ & - & & & & & & \\
\hline & ESN & $0.537 *$ & 0.233 & $0.703 * *$ & $0.733 * *$ & $-0.495 *$ & $-0.650 *$ & $0.602 *$ & $0.659 *$ & $0.653^{*}$ & $0.828 * *$ & - & & & & & \\
\hline & ET & $0.552 *$ & -0.125 & $0.704 * *$ & $0.558^{*}$ & $-0.530 *$ & $-0.620 *$ & $0.589 *$ & $0.617^{*}$ & $0.622 *$ & 0.200 & $0.610 *$ & - & & & & \\
\hline & MSGN & 0.278 & -0.338 & $0.712 * *$ & $0.571^{*}$ & -0.327 & -0.379 & 0.377 & 0.401 & 0.386 & $0.831 * *$ & $0.720 * *$ & 0.172 & - & & & \\
\hline & MSGW & $0.551 *$ & 0.157 & $1.000 * *$ & $0.875^{* *}$ & $-0.558 *$ & $-0.692 * *$ & $0.645^{*}$ & $0.696 * *$ & $0.695 * *$ & $1.000 * *$ & $1.000 * *$ & $0.488 *$ & $0.787^{* *}$ & - & & \\
\hline & TKW & 0.417 & $0.757 * *$ & 0.417 & $0.452 *$ & -0.352 & $-0.464 *$ & 0.413 & 0.438 & $0.460 *$ & 0.332 & 0.437 & 0.331 & -0.344 & 0.315 & - & \\
\hline & YPP & $0.454 *$ & 0.305 & $0.700 * *$ & $0.784 * *$ & -0.436 & $-0.568 *$ & $0.524 *$ & $0.569 *$ & $0.566^{*}$ & $1.000 * *$ & $0.828 * *$ & 0.200 & $0.831 * *$ & $1.0000 * *$ & 0.3322 & - \\
\hline WV & NABF & - & & & & & & & & & & & & & & & \\
\hline & MLN/TN & 0.415 & - & & & & & & & & & & & & & & \\
\hline & NUEg & $0.675 * *$ & 0.046 & - & & & & & & & & & & & & & \\
\hline & $\mathrm{NUEb}$ & $0.841 * *$ & 0.312 & $0.897 * *$ & - & & & & & & & & & & & & \\
\hline & NAAF & $-0.485^{*}$ & -0.178 & $-0.619 *$ & $-0.690 * *$ & - & & & & & & & & & & & \\
\hline & CPRNGN & $-0.847 * *$ & -0.364 & $-0.729 * *$ & $-0.883 * *$ & $0.864 * *$ & - & & & & & & & & & & \\
\hline & NTAAF & $0.942 * *$ & 0.351 & $0.749 * *$ & $0.901 * *$ & $-0.743 * *$ & $-0.970 * *$ & - & & & & & & & & & \\
\hline & NC NTEAF & $0.853 * *$ & 0.344 & $0.738 * *$ & $0.883 * *$ & $-0.856 * *$ & $-0.999 * *$ & $0.973 * *$ & $k \quad-$ & & & & & & & & \\
\hline & ${ }^{\mathrm{PC}}$ CNAGNF & $0.845^{* *}$ & 0.361 & $0.728 * *$ & $0.882 * *$ & $-0.866^{* *}$ & $-1.000 * *$ & $0.969 * *$ & $0.999 * *$ & - & & & & & & & \\
\hline & $\mathrm{SN}$ & 0.390 & 0.252 & 0.602 & $0.653 *$ & -0.377 & -0.487 & 0.447 & 0.487 & $0.485^{*}$ & - & & & & & & \\
\hline & ESN & $0.484 *$ & 0.216 & $0.631^{*}$ & $0.659 *$ & -0.446 & $-0.586^{*}$ & $0.540 *$ & $0.592 *$ & $0.588^{*}$ & $0.780 * *$ & - & & & & & \\
\hline & ET & $0.464 *$ & -0.104 & $0.578^{*}$ & $0.486^{*}$ & -0.444 & $-0.524^{*}$ & $0.496^{*}$ & $0.521^{*}$ & $0.524 *$ & 0.142 & $0.545^{*}$ & - & & & & \\
\hline & MSGN & 0.238 & -0.275 & $0.575^{*}$ & $0.616^{*}$ & -0.402 & $-0.497 *$ & 0.313 & 0.335 & 0.320 & $0.654 *$ & $0.637 *$ & 0.238 & - & & & \\
\hline & MSGW & 0.398 & 0.111 & $0.700 * *$ & $0.616^{*}$ & -0.402 & $-0.497 *$ & $0.460 *$ & $0.498^{*}$ & $0.496^{*}$ & $0.873 * *$ & $0.875^{* *}$ & 0.416 & $0.747 * *$ & - & & \\
\hline & TKW & 0.336 & $0.609 *$ & 0.320 & 0.353 & -0.285 & -0.374 & 0.331 & 0.353 & 0.370 & 0.438 & 0.450 & 0.237 & -0.212 & $0.463^{*}$ & - & \\
\hline & YPP & 0.390 & 0.252 & $0.602 *$ & $0.653^{*}$ & -0.377 & $-0.487 *$ & 0.447 & $0.487 *$ & $0.485^{*}$ & $1.000 * *$ & $0.780 * *$ & 0.142 & $0.654^{*}$ & $0.873^{*}$ & 0.438 & - \\
\hline
\end{tabular}
note: GC, genetic correlation; PC, phenotypic correlation. * and **, significance at 0.05 and 0.01 probability levels, respectively. SN, spikelet number; ESN, effective spiket
number of main spikes; MSGW, grain weight of main spikes; TKW, thousand-kernel weight; YPP, yield per plant. Other abbreviations are defined in foot note of Table 1. 
Table 3. Continious

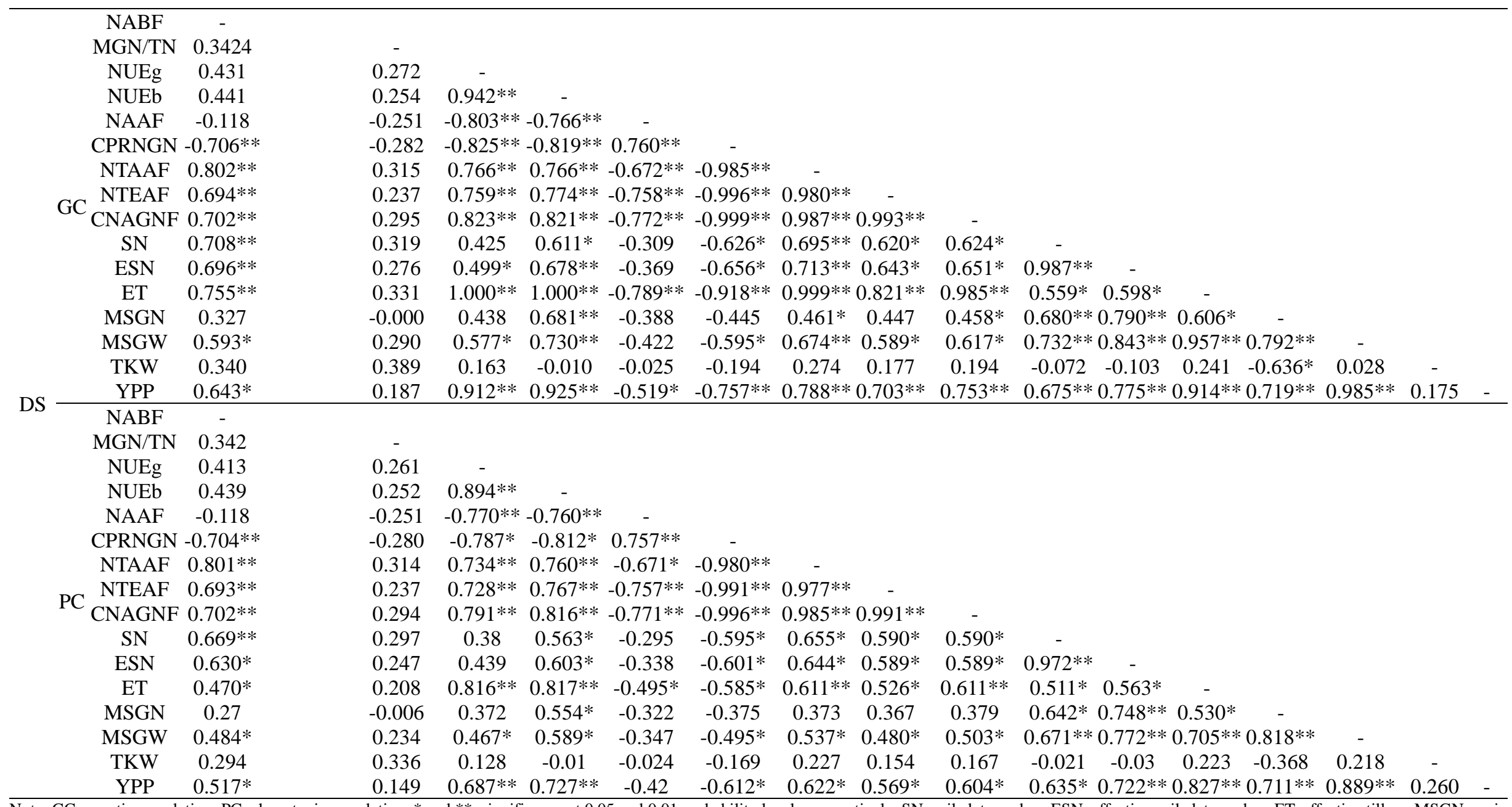

Note: GC, genetic correlation; PC, phenotypic correlation. * and **, significance at 0.05 and 0.01 probability levels, respectively. SN, spikelet number; ESN, effective spikelet number; ET, effective tillers; MSGN, grain number of main spikes; MSGW, grain weight of main spikes; TKW, thousand-kernel weight; YPP, yield per plant. Other abbreviations are defined in foot note of Table 1. 


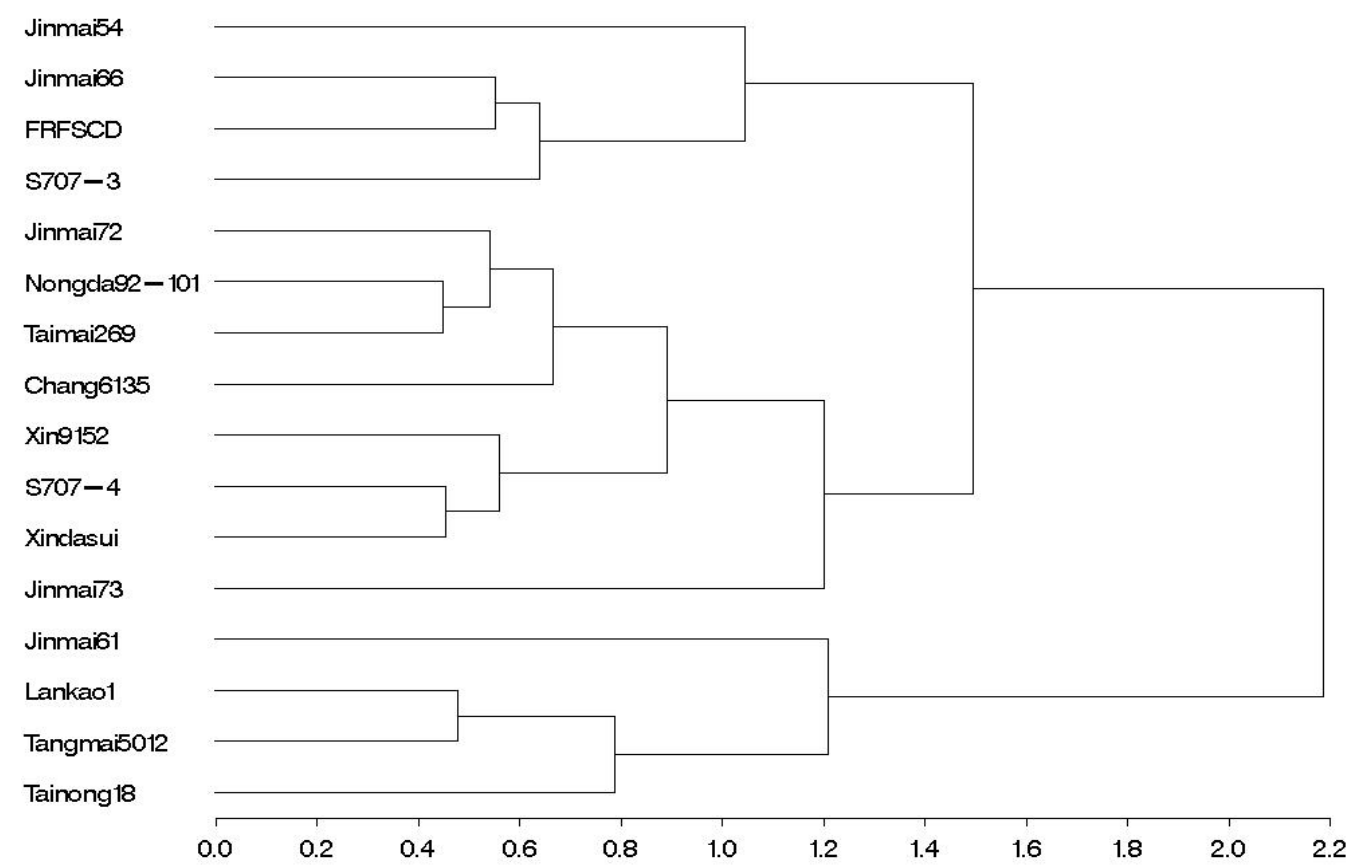

Figure 1. Clustering diagram of sixteen wheat varieties under irrigated condition

Table 4. The range of variation and mean of major nitrogen accumulation and transport-related traits and yield indicator of the three groups of clustered materials under irrigated and rainfed condition

\begin{tabular}{|c|c|c|c|c|c|c|c|}
\hline \multirow{3}{*}{ ENV } & \multirow{3}{*}{ Trait } & \multicolumn{6}{|c|}{ Group } \\
\hline & & \multicolumn{2}{|l|}{ I } & \multicolumn{2}{|l|}{ II } & \multicolumn{2}{|l|}{ III } \\
\hline & & Variation range & Mean & Variation range & Mean & Variation range & Mean \\
\hline \multirow{9}{*}{ WW } & NAAF (mg.plant ${ }^{-1}$ ) & $339.41-418.82$ & 388.06 & $266.15-348.41$ & 317.44 & $275.12-283.83$ & 279.59 \\
\hline & $\operatorname{NUEg}(\%)$ & $0.12-0.15$ & 0.14 & $0.06-0.12$ & 0.10 & $0.06-0.12$ & 0.08 \\
\hline & $\operatorname{NUEb}(\%)$ & $0.41-0.50$ & 0.45 & $0.29-0.38$ & 0.337 & $0.21-0.28$ & 0.24 \\
\hline & NTABF (mg.plant ${ }^{-1}$ ) & $132.86-155.23$ & 145.42 & $145.53-196.40$ & 169.61 & $192.70-217.20$ & 200.90 \\
\hline & CPRNGN $(\%)$ & $45.45-49.15$ & 46.93 & $56.01-73.95$ & 66.94 & $82.2-96.88$ & 87.88 \\
\hline & NAAF (mg.plant ${ }^{-1}$ ) & $206.45-272.32$ & 248.23 & $104.68-188.23$ & 139.33 & 37.09-81.77 & 63.36 \\
\hline & NTEAF $(\%)$ & 76.51-82.09 & 69.83 & $49.34-67.87$ & 56.66 & $42.44-58.98$ & 52.58 \\
\hline & CNAGNF (\%) & $53.31-56.81$ & 55.39 & $31.56-43.18$ & 37.88 & $11.49-24.09$ & 19.26 \\
\hline & YPP $\left(\right.$ g.plant $\left.{ }^{-1}\right)$ & $5.02-6.95$ & 6.13 & $3.87-5.71$ & 5.17 & $2.50-4.99$ & 3.79 \\
\hline \multirow{9}{*}{ DS } & NAAF (mg.plant $\left.{ }^{-1}\right)$ & $302.03-340.68$ & 323.79 & $240.74-322.82$ & 280.52 & $242.89-271.51$ & 258.87 \\
\hline & $\operatorname{NUEg}(\%)$ & $0.08-0.13$ & 0.10 & $0.08-0.09$ & 0.08 & $0.06-0.09$ & 0.07 \\
\hline & $\operatorname{NUEb}(\%)$ & $0.30-0.47$ & 0.37 & $0.28-0.31$ & 0.29 & $0.19-0.33$ & 0.26 \\
\hline & NTABF (mg.plant ${ }^{-1}$ ) & $47.44-73.17$ & 59.02 & $57.45-78.88$ & 64.44 & $69.73-79.10$ & 74.00 \\
\hline & CPRNGN $(\%)$ & $44.00-58.13$ & 49.59 & $56.84-67.56$ & 63.58 & $73.24-80.50$ & 76.48 \\
\hline & NAAF (mg.plant ${ }^{-1}$ ) & $181.384-220.57$ & 201.37 & $106.26-166.06$ & 128.61 & $50.88-86.35$ & 68.57 \\
\hline & NTEAF $(\%)$ & $74.15-85.99$ & 80.97 & $63.49-85.63$ & 68.67 & $53.07-59.45$ & 55.39 \\
\hline & CNAGNF (\%) & $40.12-56.41$ & 49.82 & $28.69-41.28$ & 35.06 & $14.25-23.02$ & 18.89 \\
\hline & YPP(g.plant $\left.{ }^{-1}\right)$ & $4.72-6.76$ & 5.50 & $4.22-4.81$ & 4.58 & $2.80-4.41$ & 3.47 \\
\hline
\end{tabular}

Correlation between the major nitrogen accumulation and transport indicators and yield of wheat

The uptake and utilization of nitrogen in wheat directly affected the formation of wheat yield. The yield must be taken into account, when screening of high NUE varieties. Thus, it is needed to perform a correlation analysis between the major nitrogen accumulation and transport traits and yield components. Generally, the estimated phenotypic correlation is affected by environmental factors and often does not represent the true relationships between the traits. Therefore, it is necessary to separate the phenotypic correlation into two components, genetic correlation and environmental correlation (Wang et al.,
2007). Here genetic correlation refers to the additive genetic correlation that can be fixed. In the present study, we compared the correlations between the major nitrogen accumulation and transport-related traits and the yield indicators under irrigated and rainfed conditions. Differences were found in the correlations between the indicator traits, suggesting that the water regimes had an impact on the expression of relevant traits in wheat varieties. However, there were eight nitrogen accumulation and transport-related traits showing significant or highly significant genetic correlations with YPP under both irrigated and rainfed conditions. These indicators were NAAF, NUEg, NUEb, NTAAF, NTEAF, 
CNAGNF, NTABF and CPRNGN. This indicated that these traits were less impacted by water conditions.

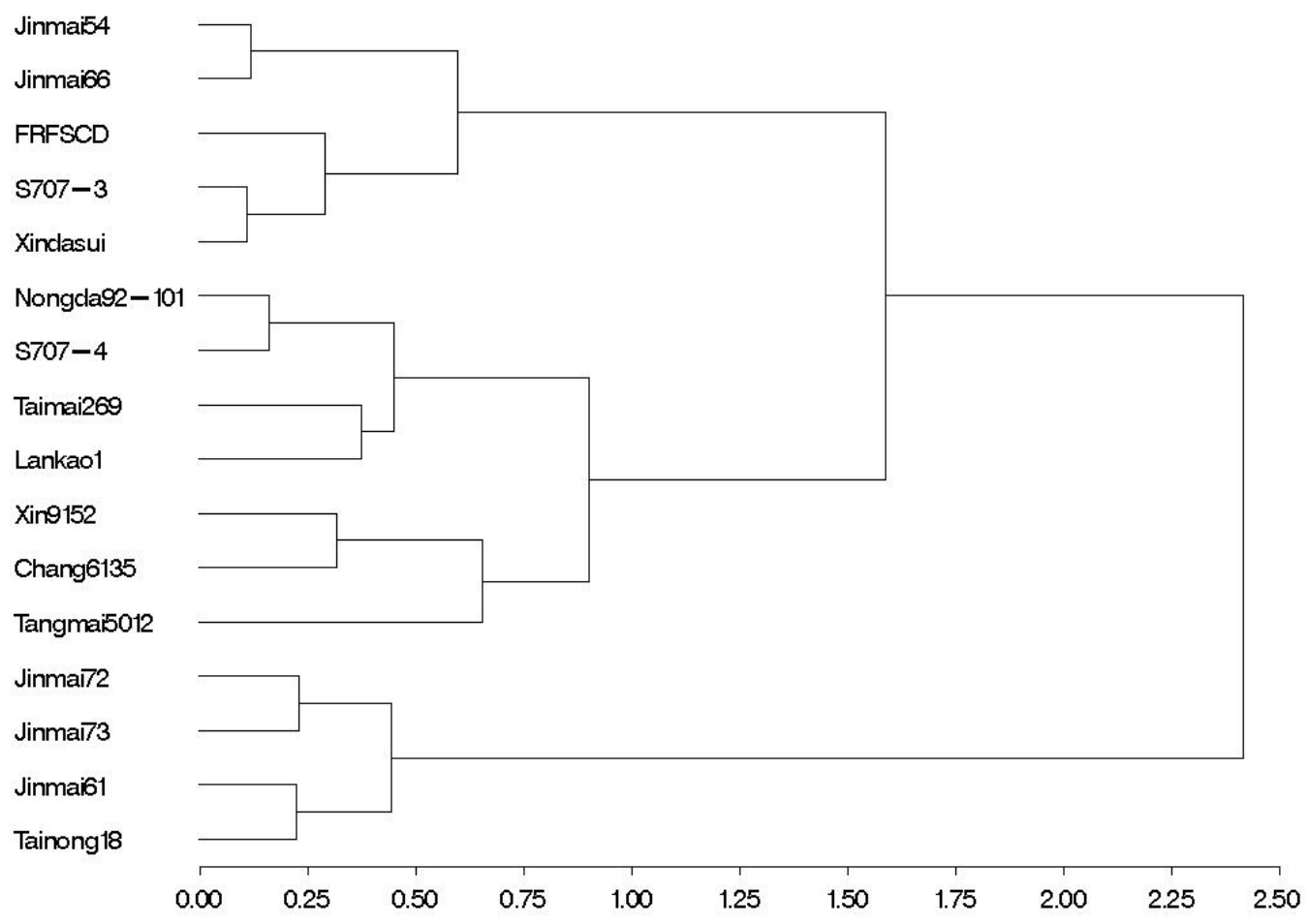

Figure 2. Clustering diagram of sixteen wheat varieties under rainfed condition

Furthermore, based on the principal component analysis and combined with the genetic correlation analysis, we finally identified these eight major indicator traits of nitrogen accumulation and transport, i.e., NAAF, NUEg, NUEb, NTAAF, NTEAF, CNAGNF, NTABF and CPRNGN. And there were significant or extremely significant genetic correlations between these traits and yield factors. This finding had important reference value for screening wheat varieties with high nitrogen efficiency.

\section{Clustering of wheat varieties under irrigated and rainfed conditions}

Based on the major nitrogen accumulation and transport indicator and yield indicator traits, the wheat varieties can be divided into different types by clustering analysis, and the characteristics of each type can be clarified. In the present study, the clustering analysis of 16 wheat varieties were performed, according to the eight nitrogen accumulation and transport-related traits screened and identified above, and in combination with YPP. Comparing the results of clustering analysis under the two water regimes, the 16 wheat varieties were classified into three groups. Group I had high mean yield and nitrogen accumulation and transport-related traits including NAAF, NUEg, NUEb, NTAAF, NTEAF, CNAGNF, and low NTABF and CPRNGN. Group III had low mean yield and nitrogen accumulation and transport-related traits including NAAF, NUEg, NUEb, NTAAF, NTEAF, CNAGNF but high NTABF and CPRNGN. Group II had an intermediate mean yield between the former two groups, as did the mean values of the major nitrogen accumulation and transport-related traits. Second, with regard to the affiliation of the type of wheat varieties, Jinmai 54, Jinmai 66, FRFSCD and S707-3 were classified into group I under the two water regimes. These four varieties had relatively high yield levels under both well-watered and drought conditions. Tainong 18 was classified into group III under both water regimes, it had relatively low yield levels under both well-watered and drought conditions. Lankao 1 and Tangmai 5012 belonged to group II under rainfed condition, with moderate yield levels. But they were classified into group III under irrigated condition, with relatively low yield levels. This indicates that these varieties were sensitive to water.

\section{CONCLUSION}

Amounts of accumulated nitrogen after flowering (NAAF), NUEg, NUEb, NTAAF, NTEAF, CNAGNF, NTABF and CPRNGN were main nitrogen accumulation and transport-related traits. There were significant or highly significant genetic correlations between these traits and YPP and yield factors under both irrigated and rainfed conditions.

In sixteen tested wheat varieties, Jinmai 54 and Jinmai 66 were high nitrogen efficient varieties with high NAAF, NUEg, NUEb, NAAF, NTEAF, CNAGNF and low NTABF, CPRNGN, while Jinmai61 and Tainong18 were low nitrogen efficient varieties with low NAAF, NUEg, 
NUEb, NAAF, NTEAF, CNAGNF and high NTABF, CPRNGN. The rest varieties were intermediate.

From the perspective of nitrogen uptake and utilization, all efforts must be made to improve NAAF, NUEg, NUEb, NTAAF, NTEAF, CNAGNF, and simultaneously decrease NTABF and CPRNGN, in order to obtain higher yields regardless of irrigated or rainfed conditions.

\section{ACKNOWLEDGEMENTS}

This work was supported by the National Transgenic Major Project of China (2018ZX0800917B), National Key R\&D Program of China (2017YFD0300202), National Natural Science Foundation of China (31671607), and Key R\&D Program in Shanxi (201703D211007-6, 201703D211007-4).

\section{LITERATURE CITED}

Erdle, K., B. Mistele and U. Schmidhalte. 2013. Spectral high-throughput assessments of phenotypic differences in biomass and nitrogen partitioning during grain filling of wheat under high yielding western European conditions. Field Crops Res. 141: 16-26.

Etienne, P., S. Pierre, M. Ian and F. Choulet. 2012. Sequence-based marker development in wheat: Advances and applications to breeding. Biotechnol. Adv. 30: 1071-1088.

Foulkes, M. J., R. Sylvester-Bradley and R. K. Scott. 1998. Evidence for differences between winter wheat cultivars in acquisition of soil mineral nitrogen and uptake and utilization of applied fertilizer nitrogen. Agric. Sci. Cam. 130: 29-44.

Graybosch, R. and C. Peterson. 2012. Specific adaptation and genetic progress for grain yield in Great Plains hard winter wheats from 1987 to 2010. Crop Sci. 52: 631-643.

Green, A., G. Berger, C. Griffey, R. Pitman, W. Thomason, M. Balota and A. Ahmed. 2012. Genetic yield improvement in soft red winter wheat in the eastern United States from 1919 to 2009. Crop Sci . 52: 2097-2108.

Gevrek, M. N. and G. D. Atasoy. 2012. Effect of post anthesis drought on certain agronomical characteristics of wheat under to different nitrogen application conditions. Turk. J. Field Crops. 17:19-23.

Horvat, D., G. Drezner, R. Sudar, G. Simici, K. Dvojkovici, V. Spanici and D. Magdici. 2015. Distribution of wheat protein components under different genetic backgrounds and environments. Turk. J. Field Crops. 20:150-154.

Karrou, J. and W. Maranville. 1994. Response of wheat cultivars to different soil nitrogen and moisture regimes: Nitrogen uptake, partitioning and influx. Plant Nutr. 17: 745-761.

Khalid, R. H., F. Khan, C. Ruby, K. Faheema, A. Altaf and I. Muhammad. 2012. Variability of nitrogen uptake and assimilation among $\mathrm{N}$-efficient and $\mathrm{N}$-inefficient wheat (Triticum aestivum L.) genotypes. J. Plant Interact. 7: 367-375.

Kong, X. B., C. Z. Li, J. Zhao, H. Y. Wang, M. Tan, T. Li and Q. P. Zhang. 2010. Method and empirical research on the realization degree of arable land production capacity at town level. Trans. Chin. Soc. Agric. Eng. 26: 345-351.

Li, D. D., M. Y. Tian, W. Cui, T. B. Dai, D. Jiang, Q. Jing and W. X. Cao. 2009. Genotypic differences of low nitrogen tolerance at wheat early stage. J. Trit. Crops. 29: 222-227.

Lobell, D. B., W. Schlenker and R. J. Costa. 2011. Caimate trends and global crop production since 1980. Science. 333: 616-620.
Lopez, M. S., M. P. Reynolds, Y. Manes, R. P. Singh, J. Crossa and H. J. Braun. 2012. Genetic yield gains and changes in associated traits of CIMMYT spring bread wheat in a "historic" set representing 30 years of breeding. Crop Sci. 52. 1123-1131.

Mohammadi, M., R. Karimizadeh, N. Sabaghnia and M. K. Shefazadeh. 2012. Genotype $\times$ environment interaction and yield stability analysis of new improved bread wheat genotypes. Turk. J. Field Crops. $17: 67-73$.

Moll, R. H., E. J. Kamprath and W. A. Jackson. 1982. Analysis and interpretation of factors which contribute to efficiency of nitrogen utilization. Agron. J. 74: 562-564.

Nadine, B., G. Philippe, G. David, C. Gilles, O. Francois-Xavier and H. Frederic. 2010. Why are wheat yields stagnating in Europe? A comprehensive data analysis for France. Field Crop Res. 119: 201-212.

Oury, F. X., C. Godin, A. Mailliard, A. Chassin, O. Gardet, A. Giraud, E. Heumez, J. Y. Morlais, B. Rolland, M. Rousset, M. Trottet and G. Charmet. 2012. A study of genetic progress due to selection reveals a negative effect of climate change on bread wheat yield in France. Eur J Agron. 40: 28-38.

Ruan, X. M., F. Z. Shi, X. H. Cong and Z. X. Luo. 2016. Analysis of rice nitrogen use efficiency based on recombinant inbred line population. Chin. J. Eco-Agric. 24: 780-789.

Ruby, C., K. Gurjeet, I. Muhammad, K. Ishrat and A. Aitaf. 2012. Differential response of wheat genotypes to applied nitrogen: biochemical and molecular analysis. Arch. Agron. Soil Sci. 58: 1130-1138.

Shi, J. F., Q. Liu, J. J. Liu, H. Xiang, Q. Z. Xie, G. Shao and Y. Q. Zhao. 2012. Development and experiment of continuous producing machine for fermented straws feed. Trans. Chin. Soc. Agric. Eng. 28: 33-38.

Shi, Y. G., H. W. Shi, H. Y. Wang, X. Yan, J. W. Yang, S. G. Wang and D. Z. Sun. 2017. Genetic correlation analysis of photosynthetic characteristics, yield and drought resistance in spring wheat(Triticum aestivum). Int. J. Agric. Biol. 19: 99-104.

Townsend, A. R. and R. W. Howarth, 2010. Fixing the global nitrogen problem. Sci. Am. 302: 64-71.

Tu, W., J. K. Lin, S. Y. Liu and Y. L. Zhao. 2013. Determination of ammonia in Pearl River estuary water using Smartchem200 automatic chemical analyzer. Anal. Instru. 26: 26-28.

Vose, P. B. 1984. Effects of genetic factors on nutritional requirements of plant. Crop breeding, acomtemporary basis. $1^{\text {th }}$ edition. perg. press, Oxford, Brit.

Wang, D., X. G. Sang, J. Zhou, J. G. Man, S. B. Gu, L. Wang, C. F. Xiang and Y. Lu. 2010. Differences in accumulation and distribution and use efficiency of nitrogen and sulfur in different types of winter wheat. Sci. Agric. Sin. 43: 4587-4597.

Wang, R. Q., L. P. Cao and Z. S. Yan. 2007. Inheritance and correlation analysis for yield traits in triticale. Seed. 26: 60-62.

Wang, T. and C. H. Lu. 2012. Estimation of food grain demand per capita based on rational dietary pattern. Trans. Chin. Soc. Agric. Eng. 28: 273-277.

Wang, X L., Y. Y. Tao, H. J. Sheng and K. Feng. 2010. Effects of nitrate supply on morphology development and nitrate uptake kinetics of wheat roots. J. Trit. Crops. 30: 129-134.

Xu, Q., F. C. Xu, J. Dong, J. H. Dong, D. D. Qin, M. Y. Lu and M. F. Li. 2017. Genotypic difference of nitrogen use efficiency of wheat and correlation analysis of the related characters. Sci. Agric. Sin. 50: 2647-2657. 
Yao. J. B., H. X. Ma, X. M. Yang, M. P. Zhou and D. Yang. 2014. Genetic analysis of the grain protein content in soft red winter wheat (Triticum aestivum L.). Turk. J. Field Crops 19: 246-251.

Zhang, Y., J. Zhang, X. M. Qiang, B. N. Zhai and C. H. Wang. 2010. Comparative study on physiological characteristics in winter wheat with different nitrogen use efficiency. Plant Nutr. Fert. Sci. 16: 1319-1324.

Zhao, G., S. Y. Wang, Y. Wang, S. Z. Li, X. M. Tang, J. J. Zhang, L. Wang and Y. Dong. 2010. Study on difference of nitrogen uptake efficacy in the different wheat varieties. Acta Agric. Boreali-Sini. 25: 180-185.

Zhou, S. L., F. S. Zhang, Y. R. Wang, G. H. Mi and D. R. Mao. 2000. A comparative study on nitrogen uptake and utilization of winter wheat varieties under high-yield conditions. Soil Fert. 6: 20-23. 